\title{
Rapid Expression of Fibronectin in the Rabbit Heart after Myocardial Infarction with and without Reperfusion
}

\author{
Anne A. Knowlton, Carolyn M. Connelly, Gabriel M. Romo, Wilfred Mamuya, Carl S. Apstein, and Peter Brecher \\ With the technical assistance of Soeun Ngoy \\ Biochemistry Department, Whitaker Cardiovascular Institute, Cardiac Muscle Research Laboratory, and Thorndike Memorial \\ Laboratories, Boston University School of Medicine and Boston City Hospital, Boston, Massachusetts 02118
}

\begin{abstract}
The expression of fibronectin in the repair process after myocardial infarction was studied using two protocols of coronary occlusion in the rabbit: a permanent occlusion or $3 \mathrm{~h}$ of occlusion followed by reperfusion (too late for salvage). We found a rapid and progressive increase in cardiac fibronectin expression in the infarcted region of the ventricle. Steady-state mRNA levels for fibronectin increased 13- and 16-fold, respectively, in the permanent and reperfused infarcts $1 \mathrm{~d}$ postinfarction. Immunological detection of the protein with a polyclonal antibody against plasma fibronectin showed significant increases of the protein fibronectin in the infarcted myocardium by day 3 in the reperfused group and by day 5 in the permanent coronary occlusion group. Ribonuclease protection assays established the induction of EIIIB containing fibronectin mRNA in both models by day 1 and use of a monoclonal antibody showed an increase in the EIIIA isoform 2 d postinfarction. Increases in steadystate mRNA levels for several collagen types were found in both groups, but these changes occurred after those noted for fibronectin. Thus fibronectin mRNA and protein expression increased rapidly postinfarction suggesting a functional role in the repair process. (J. Clin. Invest. 1992. 89:1060-1068.) Key words: collagen • extracellular matrix • glyceraldehyde-3-phosphate dehydrogenase $\bullet$ infarct healing $\bullet$ wound healing
\end{abstract}

\section{Introduction}

An understanding of the remodeling process that occurs in the heart after an acute myocardial infarction is important both for the design of appropriate therapeutic interventions and as a relevant model for the study of the molecular events associated with wound repair. Changes in the extracellular matrix comprise an important part of the wound repair process, and this topic has been studied extensively, particularly with respect to collagen content and alterations in tensile strength and compliance (1-5). Fibronectin is an important component of the extracellular matrix that is thought to have a functional role in diverse cellular processes, including wound healing (6-8). Fibronectin is a dimeric glycoprotein with a molecular mass of

This study was presented in part at the 1990 American Heart Associations Scientific Sessions.

Address reprint requests to Dr. Knowlton, R-215, Boston University School of Medicine, 80 East Concord Street, Boston, MA 02118.

Received for publication 29 July 1991 and in revised form 29 October 1991.

J. Clin. Invest.

(c) The American Society for Clinical Investigation, Inc. $0021-9738 / 92 / 04 / 1060 / 09 \$ 2.00$

Volume 89, April 1992, 1060-1068 $\sim 500 \mathrm{kD}$ that is made by most cell types and is present in plasma as well as within the extracellular matrix. It is the product of a single gene, but is subject to alternative splicing (9). The circulating form of fibronectin, made primarily by the liver, lacks the protein segments encoded by two exons designated EIIIA and EIIIB $(9,10)$. Molecules containing the segments derived from either or both of these exons are made by many nonhepatic cells, and such forms of fibronectin are commonly expressed during the wound healing process.

Much of the published data relating fibronectin to the wound healing process has been obtained using in vitro systems, although recent studies have included in vivo models where immunocytochemical and in situ hybridization techniques were used to show temporal relationships between the alternatively spliced forms of fibronectin made by distinct cell types and the different phases of wound healing (8). One major observation was the selective transcription of EIIIA and EIIIB containing mRNAs by proliferating fibroblasts in skin wounds. Both newly synthesized fibronectin and circulating fibronectin accumulate within the wound site and either form could serve as an attractant for infiltrating monocytes or neutrophils, a support for migration of infiltrating fibroblasts, or as a matrix for fibrillar formation of collagen and other extracellular components.

There is very little information available on the role of fibronectin in the heart. Ahumada et al. (11) examined the cardiac distribution of fibronectin in fetal, neonatal, and adult rat hearts. Using immunocytochemical techniques, an increase in fibronectin within $2 \mathrm{~d}$ of aortic banding has been reported in a rat model of cardiac hypertrophy (12). Others have also demonstrated the presence of fibronectin in healing infarcts by immunocytochemistry $(13,14)$. A recent histochemical study documented changes in fibronectin content following an infarct, and found early deposition of fibronectin within myocytes followed by deposition between myocytes at $48 \mathrm{~h}$ (15).

In the current study we have used a model of myocardial infarction in the rabbit heart to measure changes in both steady-state mRNA and immunodetectable protein during the first $5 \mathrm{~d}$ postinfarction. In this model, the coronary artery was either permanently occluded or reperfused at a time shown previously to be too late for myocyte salvage (5). This enabled us not only to quantitate changes in fibronectin postinfarction, but to assess the effect of late reperfusion on the expression of fibronectin. The protocol was designed to specifically evaluate the effect of reperfusion after there was no possibility of myocyte salvage. Reperfusion is the standard therapy for myocardial infarction, and there is increasing evidence that a patent artery, even after myocyte viability is lost, improves morbidity and mortality (1). Comparative studies were performed to determine the effect of late reperfusion on the expression of collagen. 


\section{Methods}

In this study 91 male New Zealand rabbits, $1.5-2.2 \mathrm{~kg}$, underwent intubation, thoracotomy, and coronary artery ligation as previously described (16). Anesthesia was obtained with a combination of pentobarbital and lidocaine. The coronary artery was either permanently occluded with a silk suture, or temporarily occluded for $3 \mathrm{~h}$ and then reperfused. Coronary occlusion was confirmed by visual inspection for pallor and dyskinesis; reperfusion was verified by visual inspection for hyperemia. This model consistently produces an infarct of $27 \pm 2 \%$ of the anterior apical region of the left ventricle by weight that is easily identifiable macroscopically at $24 \mathrm{~h}(17-19)$. The demarcation between infarct and normal tissue is particularly clear on the endocardial surface. In the nonreperfused infarct a marked pallor surrounded by a thin hemorrhagic belt is evident; in the reperfused infarct the infarcted region is hemorrhagic. The central infarct region was dissected from the noninfarcted region by visual inspection as described previously (18, 19). There were 17 postoperative deaths ( 7 in the permanent group, 10 in the reperfused group). Four hearts were not used owing to the absence of an infarct. Rabbits were overdosed with intravenous pentobarbital 1,2,3, and $5 \mathrm{~d}$ after coronary ligation at exactly $27,51,75$, and $123 \mathrm{~h}$. For RNA isolation the infarct region was rapidly dissected and frozen in liquid nitrogen. Hearts used for protein analysis were flushed from the aortic cuff with $20 \mathrm{ml}$ of normal saline to remove the blood from the intravascular space, and the infarct region was removed and frozen in liquid nitrogen. Normal hearts were prepared in the same manner for RNA and protein samples.

$R N A$ isolation. RNA was isolated by the method of Chirgwin et al. (20). RNA samples were separated on $0.9 \%$ agarose gels and then transferred to a nylon membrane (Genescreen, New England Nuclear, Boston, MA) by vacuum transfer (Stratavac, Stratagene Inc., La Jolla, CA). Hybridization was performed at $65^{\circ} \mathrm{C}$ overnight using the designated probes labeled by random hexamer priming with $\left[{ }^{32} \mathrm{P}\right] \mathrm{dCTP}$. The membranes were then washed with $0.8 \%$ SSC and $0.2 \%$ SDS at $55^{\circ} \mathrm{C}$ for $15 \mathrm{~min}$, followed by $0.5 \% \mathrm{SSC}$ and $0.5 \% \mathrm{SDS}$ at $55^{\circ} \mathrm{C}$ for $15 \mathrm{~min}$. Blots were exposed to preflashed X-Omat film (Eastman Kodak Co., Rochester, MN) at $-70^{\circ} \mathrm{C}$. Quantitation was carried out by dot blot analysis. 1, 2, and $4 \mu \mathrm{g}$ of each RNA sample was applied to a nylon membrane as described previously (21), and the membranes were processed as described above. To compare all samples within a given experimental group, more than one membrane was required. Each membrane contained 10 samples used as internal controls, and densitometric analysis between blots was normalized using these samples. RNA from normal left ventricles was used as a control on all blots. Densitometry was carried out using an Ultrascan XL (LKB Produkter, Bromma, Sweden).

$c D N A$. For fibronectin the EcoRI insert from $\lambda$ rlf- 1 and prFN-A and prFN-B were used (9). These plasmids were the generous gift of R. O. Hynes (Massachusetts Institute of Technology). Rat collagen $\alpha 1$ (I) (pa1R1) was obtained from D. Rowe (University of Connecticut Health Center, Farmington, CT) (22). The cDNA for collagen III was obtained from Benoit de Crombrugghe (M.D. Anderson Cancer Center, Houston, TX). The HincII/EcoRV 330-bp segment was used from pDT1505, which contains exon 52 of collagen III (23). The EcoRI/Hind III 1.9-kB insert of PE123 was used for collagen $\alpha 1$ (IV) (24). For glyceraldehyde-3-phosphate dehydrogenase (GAPD), ${ }^{1}$ the 500-bp Hind III/XbaI fragment of pUC13 (American Type Culture Collection, Rockville, MD) was used (25).

Ribonuclease protection assay. A ribonuclease protection assay was performed using a kit developed by Ambion, Inc., Austin, Texas. After synthesis of probes for EIIIA and EIIIB using either $\left[{ }^{35} \mathrm{~S}\right] \mathrm{CTP}$ or $\left[{ }^{32} \mathrm{P}\right]-$ CTP (New England Nuclear), hybridization with RNA samples was carried out overnight at $42-45^{\circ} \mathrm{C}$. Samples were then digested with RNase A (0.1 U) and RNase T1 (20 U) for $35 \mathrm{~min}$. The samples were

1. Abbreviation used in this paper: GAPD, glyceraldehyde-3-phosphate dehydrogenase. treated with proteinase $\mathrm{K}$, and phenol extraction was done followed by ethanol precipitation at $-70^{\circ} \mathrm{C}$. Samples were separated on an $8 \%$ sequencing gel. The gel was dried and exposed to $\mathrm{x}$-ray film from overnight to $3 \mathrm{wk}$ depending on the radioactive label used and on the intensity of the signal. After development of the autoradiograph, the bands were aligned with the gel, and the corresponding sections of the gel cut out and the radioactivity measured by scintillation counting (LKB Produkter). As comparable results were obtained by direct counting of the gel and densitometry, analysis of the reported results was done only by laser densitometry (Molecular Dynamics, Sunnyvale, CA).

The cDNA probes for EIIIA and EIIIB contain both the alternatively spliced segment and an overlapping segment with plasma fibronectin RNA, which is 109 and $100 \mathrm{bp}$ in length, respectively. Thus RNA containing EIIIA generates a 280-bp ( + ) fragment in the ribonuclease protection assay, whereas RNA lacking the EIIIA segment generates a 100-bp segment, or "minus" segment (-). For EIIIB the corresponding segments are $350 \mathrm{bp} \mathrm{(+)} \mathrm{and} 109 \mathrm{bp} \mathrm{(-).} \mathrm{The} \mathrm{minus} \mathrm{segment}$ provides an internal control for the assay and allows a direct measurement of the relative abundance of the different forms of fibronectin mRNA. The percent of EIIIB $(+)$ fibronectin was calculated by first dividing the densitometry signal for the $(+)$ form by 3.21 , then dividing by the sum of the signals for both the $(+)$ and $(-)$ segments, and then multiplying by 100 .

Protein analysis. Tissue samples were homogenized in ice-cold 0.1 $\mathbf{M}$ phosphate-buffered saline containing protease inhibitors as previously described (26). The homogenate was then centrifuged at $25,000 \mathrm{~g}$ at $4^{\circ} \mathrm{C}$ for $20 \mathrm{~min}$. The supernatant was removed, and the pellet was resuspended in $4 \%$ SDS and heated at $100^{\circ} \mathrm{C}$ for $5 \mathrm{~min}$. Samples were then centrifuged for 1 min to remove particulate matter, aliquoted, and stored at $-70^{\circ} \mathrm{C}$. Preliminary Western blot analysis demonstrated that the majority of the fibronectin was located in the SDS fraction. Samples for fibronectin analysis were separated by SDS-PAGE using $8 \%$ polyacrylamide, and then transferred to nitrocellulose (Bio-Rad Laboratories, Richmond, CA) at $4^{\circ} \mathrm{C}$ with $0.5 \mathrm{~A}$ for $5 \mathrm{~h}$ or $0.1 \mathrm{~A}$ for $24 \mathrm{~h}$ based on the method of Trotter et al. (27). Membranes were blocked with 5\% milk powder in Tris-buffered saline with $0.05 \%$ Tween 20 for 1 $h$ at $37^{\circ} \mathrm{C}$. Incubation with the first antibody was carried out either for $2 \mathrm{~h}$ at room temperature or overnight at $4^{\circ} \mathrm{C}$. A polyclonal anti-rabbit plasma fibronectin (The Binding Site, San Diego, CA) was used in a 1:5,000 dilution. After washing with buffer, incubation with an antisheep horseradish peroxidase-linked second antibody (The Binding Site) at 1:5,000 dilution was carried out for $1 \mathrm{~h}$. The membranes were developed using a chemoluminescent system (ECL, Amersham Corp., Arlington Heights, IL) according to the directions of the manufacturer. Membranes were exposed to X-Omat film for $30 \mathrm{~s}$ to $15 \mathrm{~min}$, depending on signal strength. The results were analyzed using laser densitometry. After development with the ECL system, all Western blots were stained with India ink to confirm the presence of equivalent amounts of protein on the nitrocellulose.

EIIIA Western blotting. Using the same methodology described above, Western blot analysis was performed to examine the amount of fibronectin present containing the EIIIA alternatively spliced segment. A mouse monoclonal antibody to EIIIA was the generous gift of Dr. Luciano Zardi (Cell Biology Laboratory, Instituto Nazionale per la Ricerca sul Cancro, Genoa, Italy, $(28,29)$. An anti-mouse IgG-horseradish peroxidase (Amersham Corp.) was used in a 1:2000 dilution as the second antibody. Blots were developed as described above.

Dot blot analysis. 2, 4, and $10 \mu \mathrm{g}$ of total protein from individual samples were applied to a nitrocellulose membrane using a dot blot apparatus (Bio-Rad Laboratories). The membrane was washed in Trisbuffered saline with $0.05 \%$ Tween 20 and then developed as described above for Western blotting. The anti-fibronectin antibody was used in a 1:5,000 dilution, and the second antibody was used in a 1:4,000 dilution. The same procedure was repeated for analysis using the monoclonal antibody to EIIIA. For this antibody, the methods were identical with those described under Western blotting. The blots were then exposed to X-Omat film for 1-5 min. The results were analyzed by using laser densitometry. 
Statistical analysis. Differences among groups were tested by a one way analysis of variance. The unpaired Student $t$ test was then used to determine significance. A $P$ value of $<0.05$ was considered significant. Data is expressed as the mean \pm SEM unless stated otherwise.

\section{Results}

Fibronectin. Fig. $1 A$ summarizes the results of densitometric analysis of dot blots using total RNA from normal hearts and hearts 1, 2, 3, or $5 \mathrm{~d}$ postinfarction. Each time point represents the average of three to six rabbits. When compared with con-

\section{FIBRONECTIN RNA POST MI}
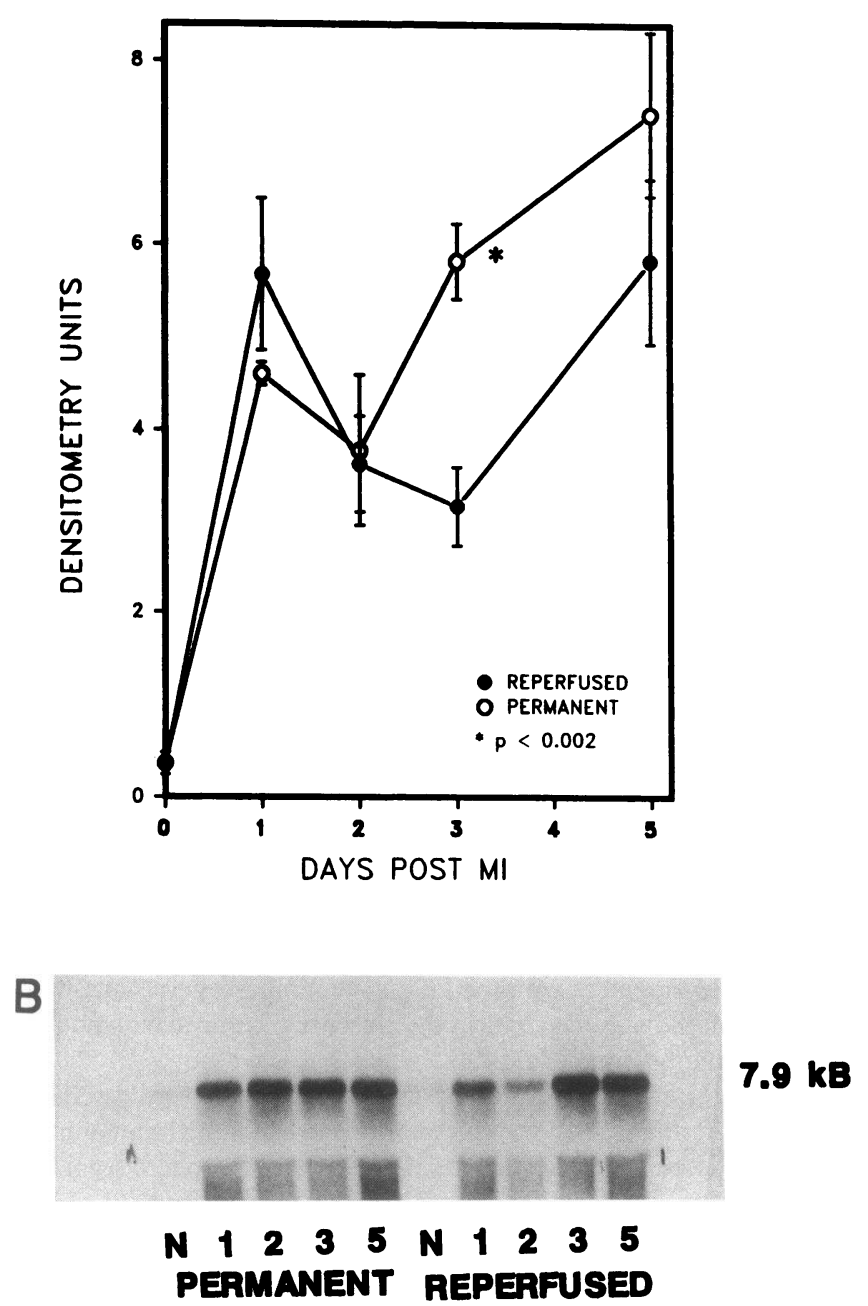

Figure 1. (A) Total fibronectin mRNA was compared between permanent infarcts (O) and late-reperfused infarcts (๑) using dot blot analysis. The time point for day 0 represents normal ventricular tissue. For the permanent infarcts for each time point $n=4$ (day 1 ), 4 (day 2), 6 (day 3), and 4 (day 5). For the late-reperfused infarcts $n=3$, 5,5 , and 3 , respectively. All points are \pm SEM. At all days fibronectin levels were significantly greater than normal $(P \leq 0.005)$. ${ }^{*}$ At day 3 levels for permanent infarcts were significantly higher than levels for late-reperfused infarcts on day $3(P<0.002)$. MI, myocardial infarction. $(B)$ A representative Northern blot showing the observed increase in expression. $N$, normal; the numbers refer to days postinfarction. trol ventricular tissue, taken from normal rabbits, there was a marked induction of fibronectin $\mathrm{mRNA}$ in the infarcted tissue in both the permanent occlusion group and in the late-reperfusion group. By day 1 fibronectin mRNA increased 13- and 16-fold in the permanently occluded and late-reperfused groups, respectively. Overall no significant differences could be found between groups, although there was a statistically significant difference on day 3 using an unpaired $t$ test, with higher levels found in the group subjected to permanent occlusion. In both groups fibronectin expression was significantly increased compared to normal hearts during the entire 5-d study period $(P<0.05)$. Fig. $1 B$ shows a representative Northern blot comparing the steady-state mRNA levels for fibronectin in the infarct region during the $5 \mathrm{~d}$ after infarction. The relatively weak signal seen for fibronectin from untreated animals (designated $N$ ) should be noted.

Collagen. Northern blot analysis also was performed on total RNA from the infarcted regions using CDNA probes for different collagen types, in that collagen is the most abundant cardiac extracellular matrix protein, and for GAPD, a constitutively expressed housekeeping gene often used to control for changes in amounts of RNA loaded onto gels. Fig. 2 shows representative data indicating an increase in steady-state mRNA for the $\alpha_{1}$ chain of both collagen types I and III in both groups. However, in contrast to fibronectin mRNA, the increases for collagen did not appear by day 1, but were apparent on day 2 and progressively increased over the next $3 \mathrm{~d}$. GAPD mRNA levels decreased during the postinfarction period in both groups, although visual inspection of the RNA loaded onto the gels and stained with ethidium bromide indicated equivalent amounts were applied.

Fig. 3 summarizes dot blot analysis for expression of the collagens and GAPD, and provides quantitative evidence for the progressive increase in collagen type I (panel l) and type III (panel 2) after day 1. The final collagen levels ranged from 6- to 12-fold greater than control ventricles, and there was no significant difference between groups at any of the time periods. Dot blot analysis was performed using a probe for collagen IV, the form of collagen present in the basement membranes (panel 3); although increases for this form of collagen were found by $1 \mathrm{~d}$ postinfarction, the progressive increases characteristic of types I and III were not as obvious. GAPD was moderately reduced to $\sim 60 \%$ of control levels by day 5 (panel 4 ) similar to observations reported in a rat model of permanent coronary occlusion (30). This decrease in GAPD may reflect a change in the distribution of cell types present in the area of necrosis.

Western blot analysis for fibronectin. To determine whether changes in fibronectin accompanied the observed increase in fibronectin mRNA, the levels of fibronectin in the samples were assessed by Western and dot blot analysis. Fig. $4 A$ summarizes the results of dot blot analysis for total fibronectin. In normal ventricle, fibronectin was barely detectable in samples containing $20 \mu \mathrm{g}$ of protein, extracted using $4 \%$ SDS as described in Methods. At $1 \mathrm{~d}$ postinfarction, fibronectin levels remained low. Fibronectin levels in the area of infarction were significantly increased compared to normal ventricle at $3 \mathrm{~d}$ postinfarction in the reperfused group $(P<0.05)$, but remained unchanged compared to normal hearts at $3 \mathrm{~d}$ postinfarction in the permanent group. Not until day 5 did the permanent infarcts show a significant increase in fibronectin protein $(P$ $<0.05)$. A representative Western blot depicting the observed changes is shown in Fig. $4 B$. 


\section{COLLAGEN a $1(\mathrm{l})$}

\author{
COLLAGEN III
}

\section{7}

5.3

\section{6}

Figure 2. Representative Northern blots illustrating the observed changes in steady-state levels of mRNA for collagen $\alpha 1$ (I), collagen III, collagen $\alpha 1$ (IV), and GAPD. Numbers at the bottom refer to days postinfarction. Late-reperfused samples are seen on the right and permanent infarcts on the left. Collagen $\alpha 1$ (I) was overexposed to show signal from normal ventricles. NL, normal.
Changes in total fibronectin could reflect either extravasation from the plasma, or local synthesis in the area of infarct. The alternatively spliced forms of fibronectin containing EIIIA or EIIIB are specific for tissue, in that neither the EIIIA nor EIIIB segments are found in plasma fibronectin. The availability of a monoclonal antibody specific for the EIIIA region of fibronectin isoforms made possible an assessment of synthesis of fibronectin in the infarct. Dot blot analysis was again used to allow simultaneous comparison of multiple samples as summarized in Fig. $5 \mathrm{~A}$. In normal hearts and 1-d-old infarcts the EIIIA form was undetectable. In the reperfused infarcts EIIIA was greatly increased compared with normal ventricle at both day 2 and day $3(P<0.01)$. This increase in EIIIA persisted at day 5 compared to normal hearts $(P<0.05)$, but was less marked. In the permanent infarcts, a similar sharp rise in EIIIA containing fibronectin occurred on the second day $(P<0.05$ vs. normal ventricle, $P=$ ns vs. reperfused). However, both the dot blot analysis and Western blot analysis as shown in Fig. $5 \mathrm{~B}$, with confirmation of equal amounts of protein by SDS-PAGE, revealed a marked drop for EIIIA fibronectin at day 3 in the permanent infarcts $(P<0.001$ vs. day 3 reperfused). Subsequently, EIIIA levels increased significantly on day 5 postinfarction in the group with permanent coronary occlusion $(P<0.05$ vs. normal hearts and vs. day 5 reperfused). These results are summarized in Fig. 5, $A$ and $B$.

Ribonuclease protection assay. To determine if changes in alternatively spliced forms of fibronectin were selectively in- duced in the ventricles after infarction, ribonuclease protection assays were used to distinguish fibronectin mRNA moieties containing specific exons from those lacking the exon. Representative data are shown in Fig. 6. Using a probe containing RNA from the EIIIB region of rat fibronectin, it was possible to quantitate the amount of fully protected RNA in the samples, containing $\sim 350$ base pairs, relative to the amount lacking that sequence, which corresponded to a protected region of 109 base pairs (Fig. 6). By $1 \mathrm{~d}$ after treatment there was an obvious increase in both the fibronectin mRNA containing and lacking the EIIIB insert. Subsequent analysis of four to five samples at each time point showed that this increase in EIIIB persisted throughout the time period. Because no difference in the relative amounts of EIIIB ( + ) and EIIIB ( - ) fibronectin was observed between the permanent and late-reperfused infarcts, this data was combined. In normal left ventricle $5.5 \pm 1.1 \%$ of the total fibronectin mRNA contained EIIIB. This value changed over the course of $1,2,3$, and $5 \mathrm{~d}$ to mean values of $2.8 \pm 0.4 \%$, $15.5 \pm 1.9 \%, 17.9 \pm 1.6 \%$, and $11.7 \pm 2.0 \%$, respectively. At 2, 3, and $5 \mathrm{~d}$ the percentage of EIIIB (+) RNA was significantly greater than that for either normal ventricle or samples from day 1. Although the percent of EIIIB $(+)$ mRNA decreased somewhat on day 1 , the total amount of EIIIB ( +$)$ mRNA greatly increased, since the total fibronectin mRNA rose 13- to 16-fold.

Quantitation of the EIIIB isoform in rabbit heart was possible using the probes derived from rat because of the apparent 

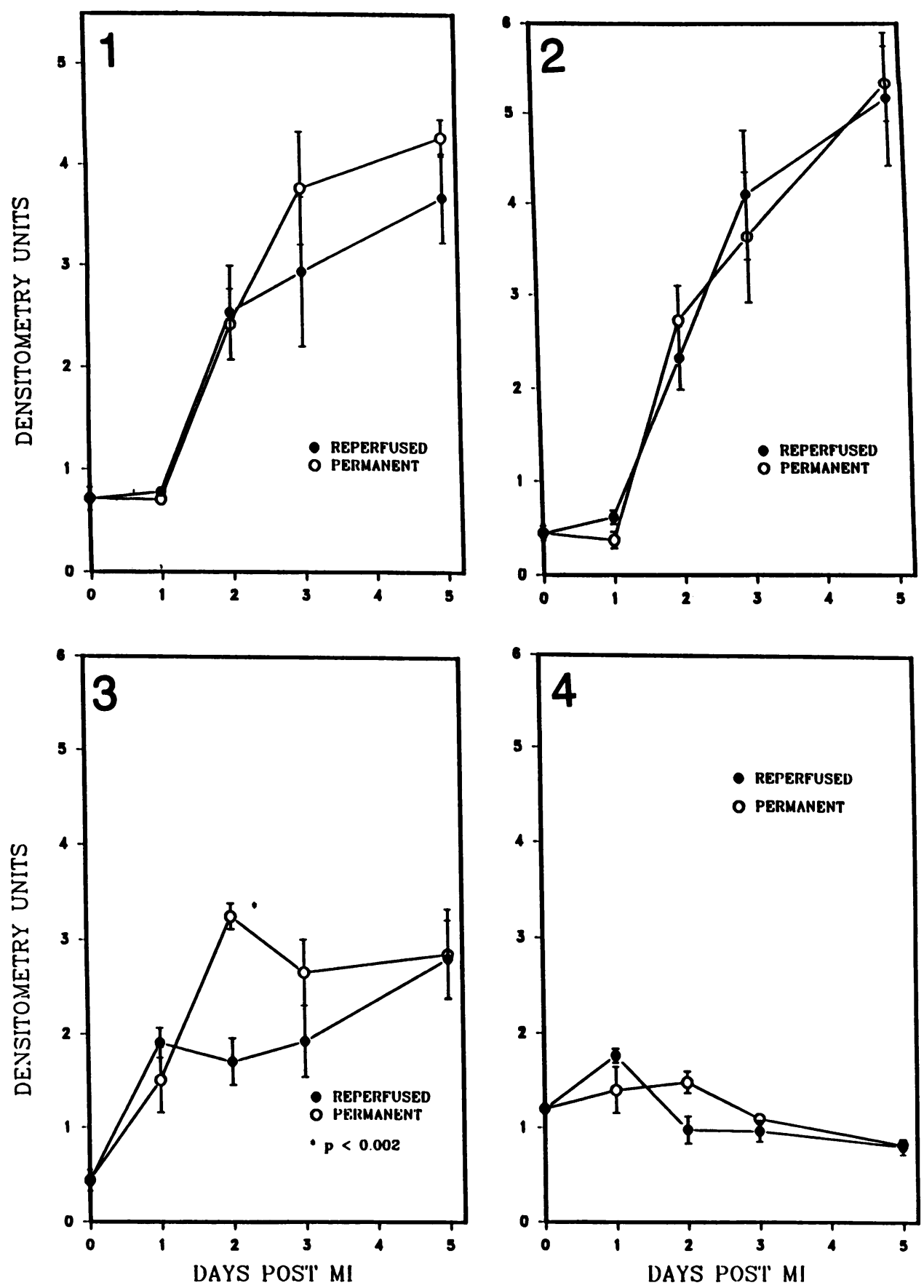

Figure 3. Dot blot analysis for the steady-state mRNA levels for collagen $\alpha 1$ (I) (panel 1); collagen III (panel 2); collagen $\alpha 1$ (IV) (panel 3); and GAPD (panel 4). The same dot blots were used for all of these studies and for data shown in Fig. 1 $A$. Day 0 refers to normal ventricle. (๑) Late-reperfused; (0) permanent. Note: $n$ is the same as defined in the legend to Fig. $1 A$. All points are \pm SEM. MI, myocardial infarction.

identity between the sequence of rat and rabbit fibronectin mRNA in the EIIIB region and the adjacent region. Attempts were made to quantitate the fibronectin isoforms containing the EIIIA segment, but weaker homology between rat and rabbit EIIIA sequences resulted in several fragments on the gel and quantitation was not possible. Nevertheless, there was a major increase in all fragments by day 1 and this increase persisted throughout the 5-d period of the study (data not shown).

\section{Discussion}

Substantial remodeling occurs in the ventricle after myocardial infarction, and this represents a complex model of wound healing $(1,31)$. Wound healing has been extensively studied both in vivo and in vitro using other model systems, but little is known of fibronectin's role in the repair processes occurring in the infarcted myocardium. In our study we found a rapid and progressive increase in cardiac fibronectin expression in the necrotic region of the left ventricle after myocardial infarction. Large increases in the steady-state mRNA levels for fibronectin occurred within $27 \mathrm{~h}$ of coronary occlusion, and these changes preceded increases in steady-state mRNA for each of the three different forms of collagen studied.

We found that fibronectin expression increased within $1 \mathrm{~d}$ of infarction in both permanent and reperfused infarcts. Subtle differences were observed between the reperfused and permanent infarcts, with an earlier increase in total fibronectin occurring in the reperfused infarcts. Synthesis by fibroblasts and extravasation from the plasma are the most likely sources of fibronectin in the infarct (11). Fibronectin is present in normal plasma and in our studies the hearts were vigorously flushed with saline to remove fibronectin present in the intravascular 


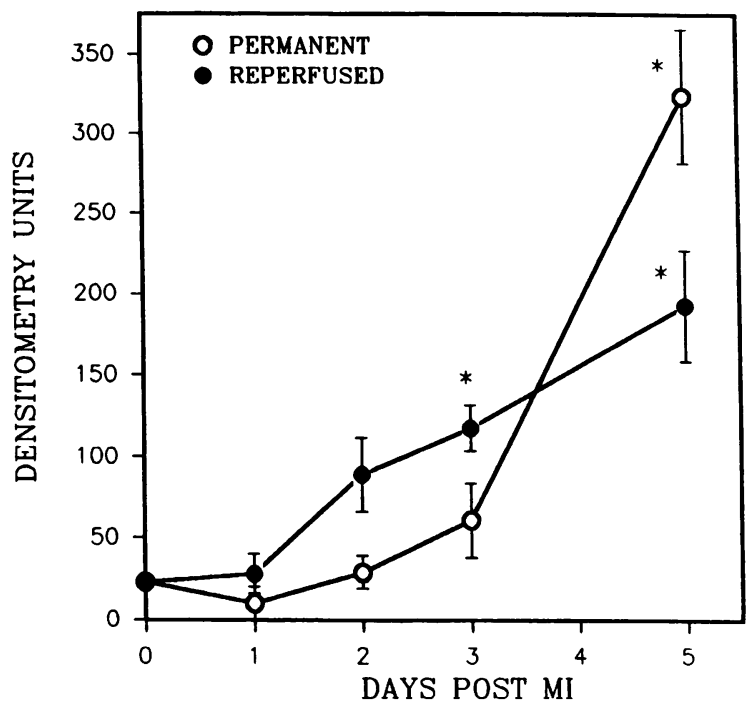

B

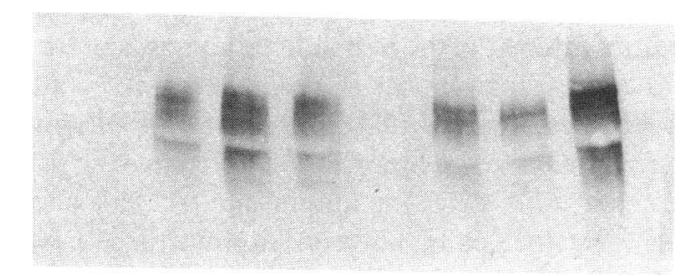

$\begin{array}{llllllll}1 & 2 & 3 & 5 & 1 & 2 & 3 & 5\end{array}$

\section{REPERFUSED PERMANENT}

Figure 4. (A) Relative total fibronectin levels in permanent (O) and late-reperfused $(\bullet)$ infarcts. Units are arbitrary densitometry units. Day 0 represents normal hearts. For the permanent infarcts, $n=2$ (day 1), 5 (day 2), 5 (day 3), and 3 (day 5), and for the late-reperfused infarcts $n=2,7,4$, and 7, respectively. All points are \pm SEM. MI, myocardial infarction. (B) Representative Western blot illustrating the changes observed in the levels of total fibronectin. Numbers at the bottom indicate days postinfarction. ${ }^{*} P<0.05$ vs. normal hearts.

space. The efficacy of this approach was indicated by the very low levels present in normal hearts prepared in this manner. Furthermore, the extraction procedure we employed involved first homogenizing the tissue in phosphate-buffered saline and centrifuging to eliminate any soluble fibronectin not tightly associated with the extracellular matrix. Subsequently, the pellet was extracted with detergent to solubilize fibronectin incorporated in the matrix (32). Therefore, the changes we observed in fibronectin levels represented matrix-associated protein and were not obscured by contamination with intravascular plasma fibronectin.

Although there was no clear difference in the amount of fibronectin mRNA present in the permanent and reperfused groups, the protein increased earlier in the reperfused infarcts. The methods employed do not distinguish between extravasation and incorporation of plasma fibronectin vs. earlier synthesis in the infarct as the etiology of the increase in total fibronectin. Western blot analysis showed that the amount of EIIIA-
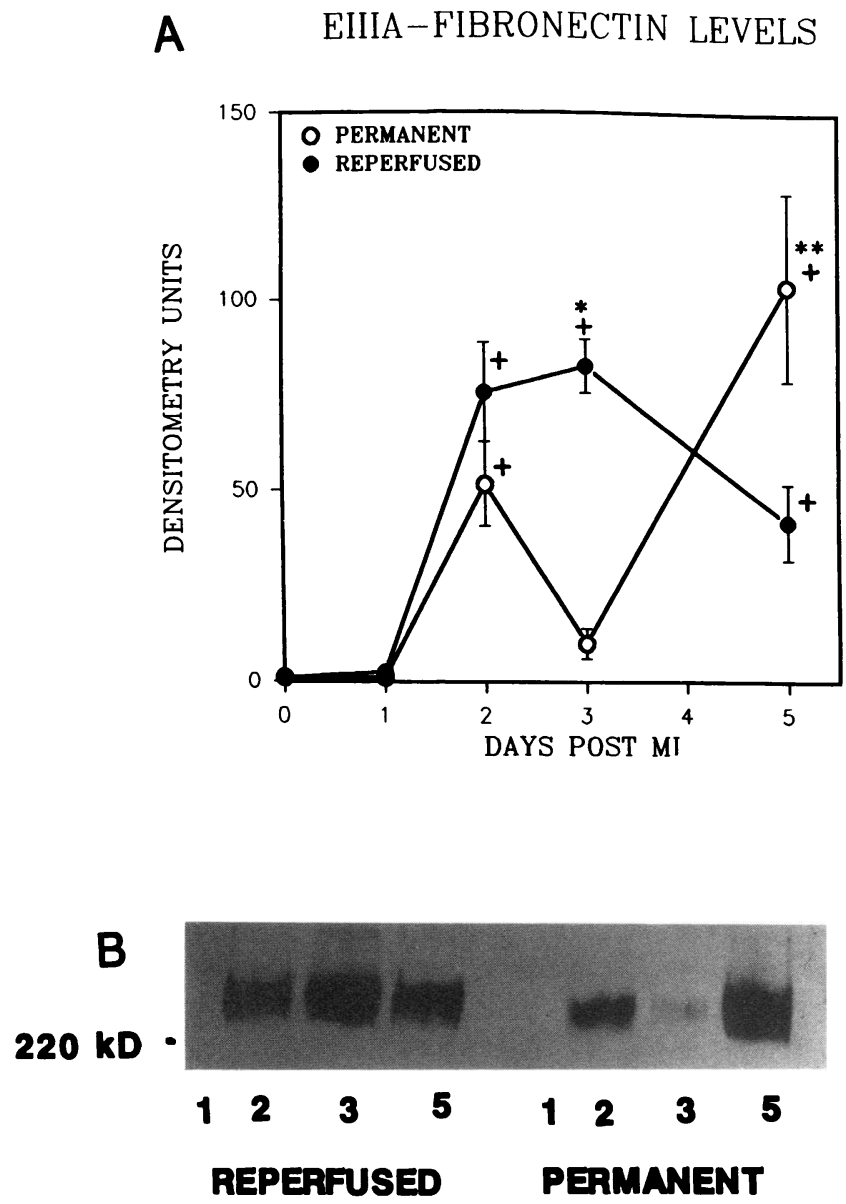

Figure 5. (A) Relative EIIIA spliced fibronectin levels in permanent $(0)$ and late-reperfused ( $\bullet$ ) infarcts. Units are arbitrary densitometry units. Day 0 represents normal ventricles. For the permanent infarcts, $n=2$ (day 1), 5 (day 2), 5 (day 3), and 4 (day 5) and for the late-reperfused infarcts $n=2,7,5$, and 7, respectively. All points are \pm SEM. ${ }^{\dagger} P<0.05$ vs. normal; ${ }^{*} P<0.001$ for 3 -d late-reperfused vs. permanent. ${ }^{* *} P<0.055$-d permanent vs. late-reperfused. MI, myocardial infarction. $(B)$ Representative Western blot illustrating the changes observed in the levels of EIIIA (+) fibronectin. Same samples and amount of protein loaded as in Fig. $4 \mathrm{~B}$. Numbers at the bottom are days postinfarction.

containing protein (cellular fibronectin) in the infarct sharply increased at day 2 for both permanent and reperfused infarcts; however, a distinct decrease in the amount of EIIIA containing protein present in the permanent infarcts was observed at day 3 followed by an increase again at day 5 . The underlying etiology of the dramatic decline on day 3 in the permanent infarcts is unclear, but the phenomenon was reproducible and found in each of the five animals used. In contrast, the levels of EIIIA containing protein remained elevated in the reperfused infarcts. A ribonuclease protection assay was used to analyze alternative splicing of fibronectin in myocardial infarction. The absolute amount of EIIIB (+) fibronectin mRNA was increased by day 1 postinfarction. These results provide clear evidence of an increase in the alternatively spliced form of fibronectin containing EIIIB within $24 \mathrm{~h}$, earlier than has been previously described in studies using immunocytochemistry (13, 15). A similar induction of both EIIIA and EIIIB has been found in healing skin wounds by in situ hybridization (8). 
EllIB

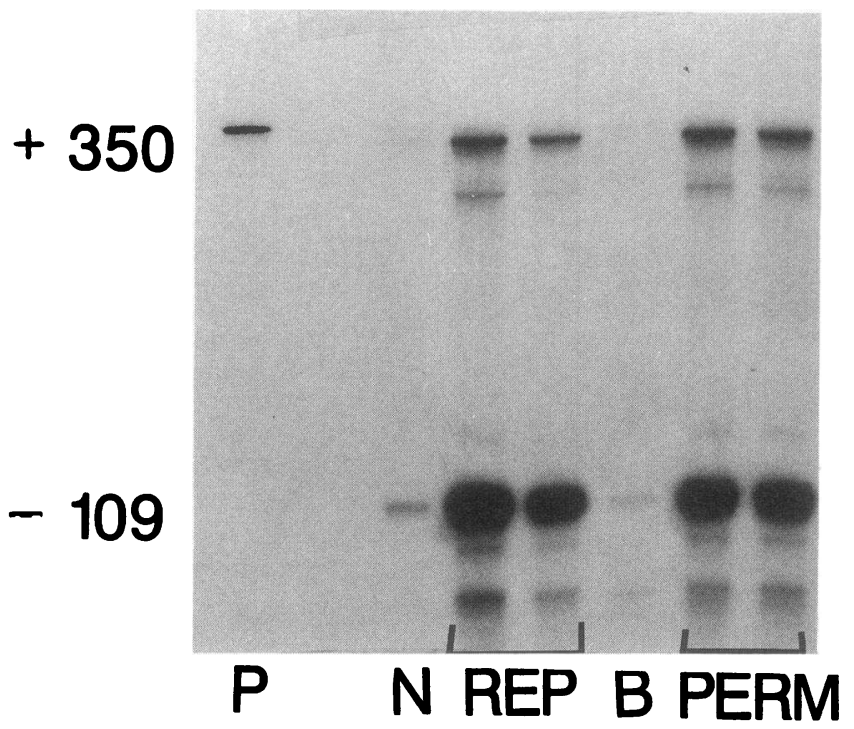

Figure 6. Representative ribonuclease protection assay for EIIIB at day 1 postinfarction. $P$, probe; $R E P, 1-\mathrm{d}$ late-reperfused; $P E R M, 1-\mathrm{d}$ permanent infarcts; $N$, normal left ventricle; $B$, sham operated. Numbers on the ordinate represent number of nucleotides.

Two immunocytochemical studies have examined the localization of fibronectin in nonreperfused myocardial infarctions in rats $(13,15)$. As early as four hours post coronary ligation, Casscells et al. (15) observed an increase in fibronectin in and around the necrotic myocyte. The accumulation of fibronectin in the myocytes persisted for $48 \mathrm{~h}$, and then diminished. It was not possible to distinguish between fibronectin deposition owing to extravasation from the plasma and local synthesis in that study because the antibody bound both plasma and cellular fibronectin. In another study of permanent coronary occlusion using a similar antibody, fibronectin deposition was also seen within three hours of infarction (13). However, in the latter study a monoclonal antibody specific to the EIIIA domain of cellular fibronectin also was used and demonstrated the complete absence of cellular fibronectin $3 \mathrm{~h}$ after infarction. $3 \mathrm{~d}$ after infarction, cellular fibronectin was found, but only in the periphery of the infarct. In the current study we were able to quantitate changes in fibronectin because of the biochemical techniques that were used. Furthermore, we examined the effect of late reperfusion, too late for myocardial salvage, which has potentially important application to the clinical setting.

Although reperfusion is a standard therapy in the management of acute myocardial infarction, studies on the effect of reperfusion on healing have been limited. Late reperfusion produces edema and hemorrhage in the infarcted region (33-35), and clinically is associated with increased survival 1 yr postinfarction $(1,36,37)$, though it may increase the incidence of early postinfarction cardiac rupture (38). Late reperfusion prematurely introduces oxygen, nutrients, leukocytes, and growth factors to the necrotic myocardium. Fewer polymorphonuclear cells were present $3 \mathrm{~d}$ postinfarction in late-perfused infarcts compared with permanently occluded coronary artery infarcts (33). At 1-3 wk postinfarction investigators found no difference in hydroxyproline levels between reperfused and permanent infarcts $(33,39)$. Reperfusion influences early postin- farction remodeling and concurrent changes in infarct composition may influence the final scar formation through alterations in the molecular framework on which collagen is deposited, rather than altering the collagen content (1).

Infarct expansion and aneurysm formation are major causes of morbidity and mortality postinfarction. Fibronectin has chemotactic properties, binds collagen, and stimulates fibroblast proliferation $(40,41)$. Those properties may contribute to the acute phase of the repair process postinfarction where cell slippage is thought to contribute to ventricular dilation and infarct expansion, both of which occur within 5-7 d postinfarction before collagen begins to accumulate to form the final scar $(1,2,37,42-45)$. Late reperfusion in animal models of infarction decreases expansion and scar thinning through unknown mechanisms $(42,46,47)$; the delivery of plasma fibronectin to the infarct through reperfusion, as supported by our data (Fig. $4 A$ as compared to relative mRNA levels in Fig. 1), may be a factor in the observed modulation of the repair process. Previously we have observed that at $3 \mathrm{~d}$ postinfarction the tear threshold of infarcts produced by 3-h coronary occlusion followed by reperfusion was higher than that of infarcts resulting from permanent occlusion (48). Autopsy data suggested that a myocardial tear is a precipitating factor for rupture postinfarction (49). In a study of infarct strength, we found that not until day 5 postinfarction did the permanent infarcts achieve a tear threshold comparable to that of reperfused infarcts (48). Thus the differences observed in fibronectin at the protein level in the current study correlate with the differences observed in tissue strength using the same animal model. This correlation may only be coincidental; however, fibronectin's known binding to collagen and the cell membrane suggests that fibronectin may have a role in this observed difference in tissue strength post-infarction.

There is a paucity of available data on collagen expression in the early stages of cardiac remodeling following infarction. The general process of wound repair is characterized by an early accumulation of fibronectin, and only in the later stages of the process does collagen production increase and replace fibronectin $(7,50)$. A similar pattern of change has recently been reported in a rat model of cardiac hypertrophy (12). In our study the increase in fibronectin mRNA preceded the changes in steady-state mRNA levels for the several different forms of collagen. Our experiments quantitated increases in the mRNA for collagen I, III, and IV. Previous studies measured hydroxyproline and demonstrated no effect of reperfusion on collagen levels at $1 \mathrm{wk}$ and beyond $(5,39)$. Likewise we observed no difference in collagen mRNA levels between reperfused and nonreperfused infarcts at the earlier times studied.

Collagen types I and III are the most abundant forms of collagen within cardiac tissue, and in the later stages of cardiac wound healing these collagen types comprise the scar tissue that replaces necrotic myocytes. mRNA for collagen IV, a basement membrane protein, increased by day 1 , whereas collagen I and III mRNA did not increase until day 2. Chapman et al. (51) observed a similar pattern in cardiac hypertrophy secondary to aortic banding, with the increase in collagen IV preceding the increase in collagens I and III (51). Collagen IV mRNA remained elevated for $7 \mathrm{~d}$ without further increase, whereas collagen types I and III mRNA declined by $7 \mathrm{~d}(51)$. This finding differs from the current study where progressive increases in the mRNA for collagen types I and III were found. The early increases in collagen IV mRNA may be related to its specific 
functions, such as providing anchoring sites for cells and aiding maintenance and development of tissue (52), compared with the fibrillar collagen types I and III, which are important in scar formation. It has been suggested that collagen types I and III are synthesized predominately by nonmyocytic fibroblasts $(53$, 54). Histochemical data suggested fibronectin is deposited around myocytes in the early response to infarction (15). Thus, the temporal differences between induction of fibronectin and collagen in our studies could reflect the action of different cell types, although the possibility cannot be excluded that myocytes, fibroblasts, and vascular tissue make both collagen and fibronectin in a temporal pattern regulated by growth factors in the infarcted region.

Our studies demonstrated that a major increase in fibronectin characterized the early phase of the healing infarct. We are the first to show that one of the tissue-specific, alternatively spliced forms of fibronectin (EIIIB) is dramatically increased 1 d postinfarction. Fibronectin may be important structurally in maintaining the tensile strength of necrotic tissue and preventing infarct expansion, as well as in organizing and regulating the repair process. The acute changes in fibronectin, preceding any increase in collagen, and fibronectin's activity as a potent mediator of cell-cell and cell-substratum interaction support an important role for fibronectin in maintaining the structural integrity of the necrotic myocardium. Although all acute infarcts are necrotic, they rarely rupture, and in fact have a tensile strength similar to normal myocardium despite consisting primarily of dead myocytes (55). Initially we were uncertain whether it would be possible to isolate any RNA from the acute, necrotic infarct. Although less RNA was present in the 1-d infarcts compared to normal myocardium, we were able at all time points postinfarction to obtain satisfactory samples.

More work is needed to define the complex series of events that characterize the healing infarct. The remodeling, which occurs in the first few days postinfarction, is a critical determinant of final ventricular size and function. The time course of these structural changes, combined with the time course of fibronectin expression are suggestive of a critical role for fibronectin in preventing expansion and providing the framework for scar formation.

\section{Acknowledgments}

Dr. Knowlton is recipient of a Physician Scientist Award (HL-01853). This study was supported in part by HL-38384 (Dr. Connelly), HL38189 (Dr. Apstein), and HL-31195 (Dr. Brecher).

\section{References}

1. Pfeffer, M. A., and E. Braunwald. 1990. Ventricular remodeling after myocardial infarction: experimental observations and clinical implications. Circulation. 81:1161-1172.

2. Weisman, H. F., D. E. Bush, J. A. Mannisi, M. L. Weisfeldt, and B. Healy. 1988. Cellular mechanisms of myocardial infarct expansion. Circulation. 78:186-201.

3. Vivaldi, M. T., D. R. Eyre, R. A. Kloner, and F. J. Schoen. 1987. Effects of methylprednisolone on collagen biosynthesis in healing acute myocardial infarction. Am. J. Cardiol. 60:424-425.

4. Stenman, S., and A. Vaheri. 1978. Distribution of a major connective tissue protein, fibronectin, in normal human tissues. J. Exp. Med. 147:1054-1064.

5. Connelly, C. M., W. M. Vogel, A. W. Wiegner, E. L. Osmers, O. H. L. Bing, R. A. Kloner, D. M. Dunn-Lanchantin, C. Franzblau, and C. S. Apstein. 1985. Effects of reperfusion after coronary artery occlusion on post-infarction scar tissue. Circ. Res. 57:562-577.

6. Murphy-Ullrich, J. E., and D. F. Mosher. 1986. Fibronectin and disease processes. In Extracellular Matrix Biochemistry. K. A. Piez and A. H. Reddi, editors. Elsevier, New York. 455-473.

7. Welch, M. P., G. F. Odland, and R. A. F. Clark. 1990. Temporal relationships of F-actin bundle formation, collagen and fibronectin matrix assembly, and fibronectin receptor expression to wound contraction. J. Cell Biol. 110:133-145.

8. ffrench-Constant, C., L. Van De Water, H. F. Dvorak, and R. O. Hynes. 1989. Reappearance of an embryonic pattern of fibronectin splicing during wound healing in the adult rat. J. Cell Biol. 109:903-914.

9. Schwarzbauer, J. E., R. S. Patel, D. Fonda, and R. O. Hynes. 1987. Multiple sites of alternative splicing of the rat fibronectin gene transcript. EMBO (Eur. Mol. Biol. Organ.) J. 6:2573-2580.

10. Hynes, R. O. 1990. Structure of fibronectins. In Fibronectins. R. O. Hynes, editor. Springer-Verlag Inc., New York. 113-175.

11. Ahumada, G. G., S. I. Rennard, A. A. Figueroa, and M. H. Silver. 1981. Cardiac fibronectin: developmental distribution and quantitative comparison of possible sites of synthesis. J. Mol. Cell. Cardiol. 13:667-678.

12. Contard, F., V. Koteliansky, F. Marotte, I. Dubus, L. Rappaport, and J. Samuel. 1991. Specific alterations in the distribution of extracellular matrix components within rat myocardium during the development of pressure overload. Lab. Invest. 64:65-75.

13. Shekhonin, B. V., S. B. Guriev, S. B. Irgashev, and V. E. Koteliansky. 1990. Immunofluorescent identification of fibronectin and fibrinogen/fibrin in experimental myocardial infarction. J. Mol. Cell. Cardiol. 22:533-541.

14. Shekhonin, B. V., S. P. Domogatsky, G. L. Idelson, and V. E. Koteliansky. 1988. Participance of fibronectin and various collagen types in the formation of fibrous extracellular matrix in cardiosclerosis. J. Mol. Cell. Cardiol. 20:501-508.

15. Casscells, W., H. Kimura, J. A. Sanchez, and V. J. Ferrans. 1990. Immunohistochemical study of fibronectin in experimental myocardial infarction. Am. J. Pathol. 137:801-810.

16. Connelly, C. M., J. A. Leppo, P. W. Weitzman, W. M. Vogel, and C. S. Apstein. 1989. Effect of coronary occlusion and reperfusion on myocardial blood flow during infarct healing. Am. J. Physiol. 257:H365-H374.

17. Connelly, C. M., W. M. Vogel, Y. M. Hernandez, and C. S. Apstein. 1982. Movement of necrotic wavefront after coronary artery occlusion in rabbit. $\mathrm{Am}$. J. Physiol. 243:H682-H690.

18. Lerman, R. H., C. S. Apstein, H. M. Kagan, E. L. Osmers, C. O. Chichester, W. M. Vogel, C. M. Connelly, and W. P. Steffee. 1983. Myocardial healing and repair after experimental infarction in the rabbit. Circ. Res. 53:378-388.

19. Connelly, C. M., R. J. McLaughlin, W. M. Vogel, and C. S. Apstein. 1991. Reversible and irreversible elongation of ischemic infarcted and healed myocardium in response to increases in preload and afterload. Circulation. 84:387-399.

20. Chirgwin, J. M., A. E. Przbyla, R. J. MacDonald, and W. J. Rutter. 1979. Isolation of biologically active ribonucleic acid from sources enriched in ribonuclease. Biochemistry. 18:5294-5299.

21. Knowlton, A. A., P. Brecher, and C. S. Apstein. 1991. Rapid expression of heat shock protein in the rabbit after brief cardiac ischemia. J. Clin. Invest. 87:139-147.

22. Genovese, C., D. Rowe, and B. Kream. 1984. Construction of DNA sequences complementary to rat $\alpha 1$ and $\alpha 2$ collagen mRNA and their use in studying the regulation of type I collagen synthesis by 1,25-dihydroxyvitamin $D$. Biochemistry. 23:6210-6216.

23. Liau, G., Y. Yamada, and B. de Crombrugghe. 1984. Coordinate regulation of types III and type I collagen mRNA in most but not all mouse fibroblasts. J. Biol. Chem. 260:531-536.

24. Kurkinen, M., M. R. Condon, B. Blumberg, D. P. Barlow, S. Quinones, J. Saus, and T. Pihlajaniem. 1987. Extensive homology between the carboxyl-terminal peptides of mouse $\alpha 1$ (IV) and $\alpha 2$ (IV) collagen. J. Biol. Chem. 262:84968499.

25. Tso, J. Y., X.-H. Sun, T. Kao, K. S. Reece, and R. Wu. 1985. Isolation and characterization of rat and human glyceraldehyde-3-phosphate dehydrogenase cDNAs: genomic complexity and molecular evolution of the gene. Nucleic Acid Res. 13:2485-2502.

26. Knowlton, A. A., R. E. Burrier, and P. Brecher. 1989. Rabbit heart fatty acid binding protein: isolation, characterization, and application of a monoclonal antibody. Circ. Res. 65:981-988.

27. Trotter, K. M., D. H. Beezhold, and D. B. Lause. 1989. Modulation of macrophage fibronectin secretion by LPS. J. Leukocyte Biol. 45:515-522.

28. Carnemolla, B., L. Borsi, L. Zardi, R. J. Owens, and F. E. Baralle. 1987. Localization of the cellular-fibronectin-specific epitope recognized by the monoclonal antibody IST-9 using fusion proteins expressed in E. coli. FEBS (Fed. Eur. Biochem. Soc.) Lett. 215:269-273.

29. Borsi, L., B. Carnemolla, P. Castellani, C. Rosellini, D. Vecchio, G. Allemanni, S. E. Chang, J. Taylor-Papadimitriou, H. Pande, and L. Zardi. 1987. Monoclonal antibodies in the analysis of fibronectin isoforms generated by alternative splicing of mRNA precursors in normal and transformed human cells. $J$ Cell Biol. 104:595-600.

30. Thompson, N. L., F. Bazoberry, E. H. Speir, W. Casscells, V. J. Ferrans, K. C. Flanders, P. Kondaiah, A. G. Geiser, and M. B. Sporn. 1988. Transforming growth factor Beta-1 in acute myocardial infarction in rats. Growth Factors. 1:9199.

31. Olivetti, G., J. M. Capasso, L. G. Meggs, E. H. Sonnenblick, and P. 
Anversa. 1991. Cellular basis of chronic ventricular remodeling after myocardial infarction in rats. Circ. Res. 68:856-869.

32. Takasaki, I., A. V. Chobanian, and P. Brecher. 1991. Biosynthesis of fibronectin by rabbit aorta. J. Biol. Chem. 266:17686-17694.

33. Roberts, C. S., F. J. Schoen, and R. A. Kloner. 1983. Effect of coronary reperfusion on myocardial hemorrhage and infarct healing. Am. J. Cardiol. 52:610-614.

34. Fujiwara, H., T. Onodera, M. Tanaka, T. Fujiwara, D. Wu, C. Kawai, and Y. Hamashima. 1986. A clinicopathologic study of patients with hemorrhagic myocardial infarction treated with selective coronary thrombolysis with urokinase. Circulation. 73:749-757.

35. Higginson, L. A. J., D. S. Beanlands, R. C. Nair, V. Temple, and K. Sheldrick. 1983. The time course and characterization of myocardial hemorrhage after coronary reperfusion in the anesthetized dog. Circulation. 67:1024-1031.

36. Braunwald, E. 1989. Myocardial reperfusion, limitation of infarct size, reduction of left ventricular function, and improved survival: should the paradigm be expanded? Circulation. 79:441-444.

37. Bonaduce, D., M. Petretta, B. Villari, R. Breglio, G. Conforti, M. V. Montemurro, T. Lanzillo, and G. Morgano. 1990. Effects of late administration of tissue-type plasminogen activator on left ventricular remodeling and function after myocardial infarction. J. Am. Coll. Cardiol. 16:1561-1568.

38. Honan, M. B., F. E. Harrell, K. A. Reimer, R. M. Califf, D. B. Mark, D. B. Pryor, and M. A. Hlatky. 1990. Cardiac rupture, mortality and the timing of thrombolytic therapy: A meta-analysis. J. Am. Coll. Cardiol. 16:359-367.

39. Geft, I. L., M. C. Fishbein, J. Hashida, K. Ninomiya, S. Nishizawa, R. Haendchen, N. Venkatesh, J. Y-Rit, J. Yano, and W. Ganz. 1984. Effects of late coronary artery reperfusion after myocardial necrosis is complete. Am. Heart J. 107:623-629.

40. Zlatopol'skii, A. D., A. N. Chubukina, and M. A. Zaidenberg. 1989. Influence of fibronectin fragments on the proliferative activity of fibroblasts. Biochemistry. 54:55-60.

41. Hynes, R. O. 1990. Interactions of fibronectins. In Fibronectins. R. O. Hynes, editor. Springer-Verlag, Inc., New York. 84-112.

42. Force, T., A. Kemper, M. Leavitt, and A. F. Parisi. 1988. Acute reduction in functional infarct expansion with late coronary reperfusion: assessment with quantitative two-dimensional echocardiography. J. Am. Coll. Cardiol. 11:192200.

43. Jugdutt, B. I., and R. W. M. Amy. 1986. Healing after myocardial infarc- tion in the dog: Changes in infarct hydroxyproline and topography. J. Am. Coll. Cardiol. 7:91-102.

44. Pfeffer, M. A., and J. M. Pfeffer. 1987. Ventricular enlargement and reduced survival after myocardial infarction. Circulation. 75:93-97.

45. Hochman, J. S., and B. H. Bulkley. 1982. Pathogenesis of left ventricular aneurysms: an experimental study in the rat model. Am. J. Cardiol. 50:83-88.

46. Hochman, J. S., and H. Choo. 1987. Limitation of myocardial infarct expansion by reperfusion independent of myocardial salvage. Circulation. 75:299-306.

47. Hale, S. L., and R. A. Kloner. 1988. Left ventricular topographic alterations in the completely healed rat infarct caused by early and late coronary artery reperfusion. Am. Heart J. 116:1508-1513.

48. Connelly, C. M., S. Ngoy, and C. S. Apstein. 1990. Left ventricular rupture potential in transmural infarcts with late reperfusion. Circulation. 82:288.

49. Mann, J. M., and W. C. Roberts. 1988. Rupture of the left ventricular free wall during acute myocardial infarction: analysis of 138 necropsy patients and comparison with 50 necropsy patients with acute myocardial infarction without rupture. Am. J. Cardiol. 62:847-859.

50. Kawahara, E., A. Mukai, Y. Oda, I. Nakanishi, and T. Iwa. 1990. Left ventriculotomy of the heart: tissue repair and localization of collagen types I, II, III, IV, V, VI, and fibronectin. Virchows Arch. (Pathol. Anat.). 417:229-236.

51. Chapman, D., K. T. Weber, and M. Eghbali. 1990. Regulation of fibrillar collagen types I and III and basement membrane type IV collagen gene expression in pressure overloaded rat myocardium. Circ. Res. 67:787-794.

52. Burgeson, R. E., and N. P. Morris. 1986. The collagen family of proteins. In Extracellular Matrix Biochemistry. K. A. Piez and A. H. Reddi, editors. Elsevier, New York. 3-28.

53. Eghbali, M., M. J. Czaja, M. Zeydel, F. R. Weiner, M. A. Zern, S. Seifter, and O. O. Blumenfeld. 1988. Collagen chain mRNAs in isolated heart cells from young and adult rats. J. Mol. Cell. Cardiol. 20:267-276.

54. Eghbali, M., O. O. Blumenfeld, S. Seifter, P. M. Buttrick, L. A. Leinwand, T. F. Robinson, M. A. Zern, and M. A. Giambrone. 1989. Localization of types I III, and IV collagen mRNAs in rat heart cells by in situ hybridization. J. Mol. Cell. Cardiol. 21:103-113.

55. Przyklenk, K., C. M. Connelly, R. J. McLaughlin, R. A. Kloner, and C. S. Apstein. 1987. Effect of myocyte necrosis on strength, strain, and stiffness of isolated myocardial strips. Am. Heart J. 114:1349-1359. 